\title{
Correlation between miR-222 and uterine cancer and its prognostic value
}

\author{
XIUJUAN NIE and HAILI TIAN \\ Department of Obstetrics and Gynecology, Dongying People's Hospital, Dongying, Shandong 257091, P.R. China
}

Received November 29, 2017; Accepted May 17, 2018

DOI: $10.3892 / \mathrm{ol} .2018 .8815$

\begin{abstract}
Relationship between the expression of miR-222 and uterine cancer was investigated to explore its prognostic value. A total of 66 patients with uterine cancer diagnosed by pathological examination in Dongying People's Hospital were enrolled from March 2014 to October 2016. Uterine cancer and adjacent tissues were collected, and the expression of miR-222 in the tissues was detected by stem-loop RT-PCR. The relationship between miR-222 expression and various clinicopathological features of uterine cancer was analyzed. All the patients were followed up to record the survival conditions. The results revealed that stem-loop RT-PCR method could specifically amplify miR-222. The expression of miR-222 in uterine cancer tissues was significantly upregulated compared with that in adjacent tissues $(\mathrm{p}<0.05)$. The expression level of miR-222 was significantly increased with the increase of degree of tumor differentiation $(\mathrm{p}<0.05)$. The expression of miR-222 in uterine cancer tissue was not significantly correlated with patients' age, tumor size, gross tumor type, pathological type and FIGO stage $(p>0.05)$. There was a significant negative correlation between the expression of miR-222 and the survival of patients with uterine cancer. In conclusion, the expression of miR-222 in uterine cancer tissues was significantly upregulated in uterine cancer and negatively correlated with prognosis. miR-222 may play a pivotal role in the development and progression of uterine cancer. It is expected that miR-222 will be an indicator and target for the treatment and prognosis of uterine cancer.
\end{abstract}

\section{Introduction}

Uterine cancer is the second most common malignancy in females and the incidence of this disease is only lower than that of breast cancer (1). According to a report released by the International Agency for Research on Cancer,

Correspondence to: Dr Xiujuan Nie, Department of Obstetrics and Gynecology, Dongying People's Hospital, 317 Nanyi Road, East District, Dongying, Shandong 257091, P.R. China

E-mail:nqpjjh@163.com

Key words: miR-222, uterine cancer, correlation, prognosis
$>300,000$ women die from uterine cancer each year, and $>80 \%$ of them are from developing countries (2). In recent years, the incidence of uterine cancer shows an increasing trend in developing countries, especially in young women, incidence of this disease increases by $3 \%$ every year (3). So far, the mechanism of uterine cancer has not been completely elucidated. Therefore, the development of new biomarkers and effective treatment targets is the key to further improve the prognosis of uterine cancer. miRNAs are a class of highly conserved endogenous regulatory RNA molecules with a length of 18-26 bp. miRNAs bind to mRNA molecules transcribed from target genes and inhibit the its translation, ultimately regulating the expression of target genes $(3,4)$. Many miRNAs, such as miR-16, miR-155 and miR-223, were upregulated in uterine cancer tissues (5), expression of some other miRNAs, such as miR-143 and miR-145, decreased in uterine cancer tissues (6), indicating that miRNAs may be key players in uterine cancer. miR-222 is highly expressed in a variety of tumors, including breast (7), bladder (8), colon (9), glioblastoma (10), and pancreatic cancer (11). However, the role of miR-222 in uterine cancer is still unclear. Therefore, in this study, the expression of miR-222 in uterine cancer and adjacent tissues was detected by stem-loop RT-PCR to investigate the relationship between miR-222 expression and clinicopathological features of this disease, so as to explore the role of miR-222 in the occurrence and development of uterine cancer and its clinical significance.

\section{Patients and methods}

\section{Patients}

Experimental data. A total of 66 patients with uterine cancer diagnosed by gynecological and pathological examination in Dongying People's Hospital (Dongying, China) were enrolled from March 2014 to October 2016. During surgical resection, uterine cancer and adjacent tissues were collected. Ages of patients ranged from 33 to 75 years. Among those patients, 27 patients had tumors $<4 \mathrm{~cm}$ in diameter and the remaining patients all had a tumor diameter $\geq 4 \mathrm{~cm}$. No patients received radiotherapy or chemotherapy before admission. Uterine cancer histopathological types: squamous cell carcinoma in 53 cases, adenocarcinoma in 9 cases, adenosquamous carcinoma in 4 cases. Uterine cancer tissue differentiation degree: 9 cases in grade I, 19 cases in grade II and 38 cases in grade III. FIGO stage: 6 cases in stage I, 25 cases in 
Table I. Primers used in stem-loop RT-PCR.

\begin{tabular}{ll}
\hline Primer & \multicolumn{1}{c}{ Sequence } \\
\hline miR-222 & \\
RT stem-loop primer & 5'-GTCGTATCCAGTGCAGGGTCCGAGGTATTCGCACTGGATACGACACCCAGTA-3' \\
Forward primer & 5'-GTTCGTFFFAFCTACATCTGGC-3' \\
let-7a & \\
RT stem-loop primer & 5'-GTCGTATCCAGTGCAGGGTCCGAGGTATTCGCACTGGATACGACAACTATAC-3' \\
Forward primer & 5'-ATGGTTCGTGGGTGAGGTAGTAGGTTGT-3' \\
Common reverse primer & 5'-GTGTCGTGGAGTCGGCAATTC-3'
\end{tabular}

stage II, 18 cases in stage III and 17 cases in stage IV. All patients or their families signed informed consent. This study was approved by the Ethics Committee of Dongying People's Hospital (Dongying, China).

Reagents and instruments. Tissue total RNA extraction kit (BioLabs Technology Co., Ltd., Beijing, China), miRNA reverse transcription kit (GeneCopoeia, Inc., Rockville, MD, USA), fluorescence quantitative PCR kit SYBR-Green (Huaxia Yuanyang Technology Co., Ltd., Beijing, China), urea (Healthdream Biological Technology Co., Ltd., Wuhan, China), ABI 7500 fluorescence quantitative PCR instrument (Thermo Fisher Scientific, Inc., Waltham, MA, USA), quantitative spectrophotometer (Jiang Xue Technology Co., Ltd., Chongqing, China).

\section{Method}

miR-222 expression analysis. Total RNA was extracted according to the manufacturer's instructions, and A260/A280 ratio was meaured using a quantitative spectrophotometer. Total RNA was reverse transcribed into cDNA in accordance with the instructions of miRNA reverse transcription kit. Reverse transcription system: $1 \mu \mathrm{g}$ total RNA, $50 \mu \mathrm{M}$ stem-loop RT primer, 2 U RNase inhibitor, $5 \mathrm{U}$ M-MLV reverse transcriptase, and $0.5 \mu \mathrm{M}$ dNTPs. Reaction conditions: $16^{\circ} \mathrm{C}$ for $30 \mathrm{~min}, 42^{\circ} \mathrm{C}$ for $30 \mathrm{~min}$ and $75^{\circ} \mathrm{C}$ for $15 \mathrm{~min}$. All cDNA samples were stored at $-20^{\circ} \mathrm{C}$. This experiment was performed 3 times (Table I).

RT-qPCR reaction system $(15 \mu \mathrm{l}): 1 \mu \mathrm{l}$ cDNA, $1 \mathrm{X}$ SYBR-Green I Mastermix, $0.5 \mu \mathrm{M}$ miRNA specific forward primer, $0.5 \mu \mathrm{M}$ universal reverse primer. Reaction conditions: $94^{\circ} \mathrm{C}$ for $10 \mathrm{~min}$, followed by 40 cycles of $95^{\circ} \mathrm{C}$ for $15 \mathrm{sec}, 60^{\circ} \mathrm{C}$ for $60 \mathrm{sec}$, and $72^{\circ} \mathrm{C}$ for $30 \mathrm{sec}$. With let-7a as endogenous control (12), the relative expression of miRNA was calculated automatically by RT-PCR instrument.

Analysis of the specificity of miR-222 stem-loop RT-PCR. A total of $5 \mu \mathrm{g}$ total RNA was used to isolate low molecular weight RNAs. After denaturing by $15 \%$ urea solution, miRNA precursor and mature miRNA were then separated by $8 \%$ PAGE. Stem-loop RT-PCR was then performed to detect miR-222. Reaction volume was $20 \mu \mathrm{l}$. First, $2 \mu \mathrm{g}$ of total RNA, $1 \mu \mathrm{l}$ of RT primer (stem-loop primer) and $1 \mu \mathrm{l}$ of dNTPs were mixed, and DEPC water was added to make a volume of $14 \mu \mathrm{l}$. After denaturation at $65^{\circ} \mathrm{C}$ for $5 \mathrm{~min}$, in the produced was kept on ice. Then $1 \mu \mathrm{l}$ of reverse transcriptase AMV, $4 \mu \mathrm{l}$ of buffer and $1 \mu \mathrm{l}$ of RNase inhibitor were added. Reaction conditions

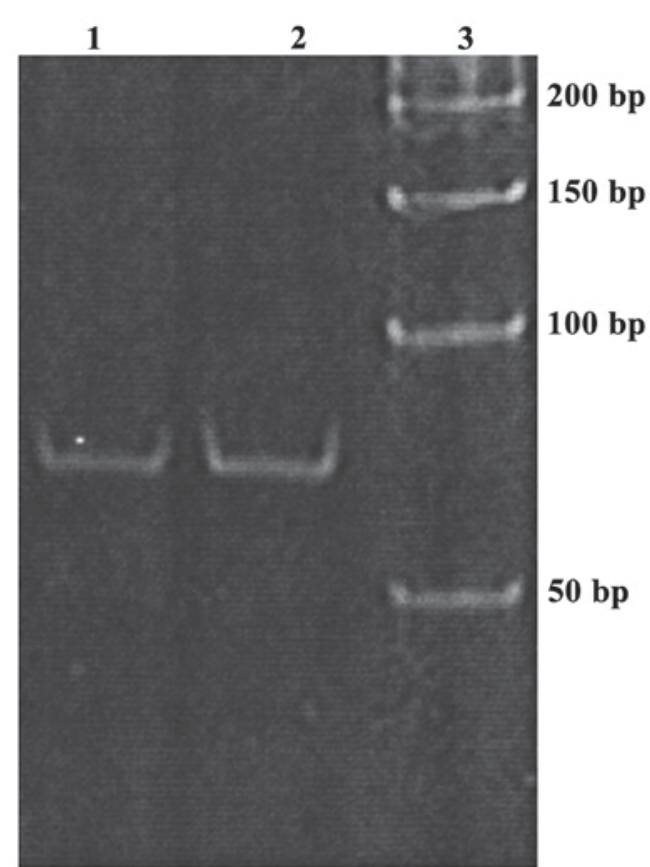

Figure 1. Results of $8 \%$ PAGE of PCR amplification product of miRNA and endogenous control let-7a. Lanes 1, 2 and 3 are miR-222, let-7a and 50 bp DNA markers, respectively. Results show that stem-loop RT-PCR method can be used to specifically amplify miR-222.

were: $16^{\circ} \mathrm{C}$ for $30 \mathrm{~min}$, followed by 60 cycles of $20^{\circ} \mathrm{C}$ for $30 \mathrm{sec}$, $42^{\circ} \mathrm{C}$ for $30 \mathrm{sec}$ and $50^{\circ} \mathrm{C}$ for $1 \mathrm{sec}$, and $85^{\circ} \mathrm{C}$ for $10 \mathrm{~min}$.

Statistical analysis. Data were analyzed using SPSS 19.0 software (Beijing Xinmei Jiahong Technology Co., Ltd., Beijing, China). Measurement data were expressed as mean \pm standard deviation, ANOVA was used for multiple group comparisons and the post hoc test was Dunnett's test. Survival analysis was performed using GraphPad Prism 5 with $\alpha=0.05$ as standard.

\section{Results}

Establishment of stem-loop RT-PCR detection method. The product of miRNA amplification by stem-loop RT-PCR showed a single band after $8 \%$ PAGE. So stem-loop RT-PCR method can specifically amplify miR-222 (Fig. 1).

As shown in Fig. 2, after 8\% PAGE, gray values of the bands derived from PCR reaction with 22 or 30 cycles were similar. PCR with 30 cycles provided a faint band, while PCR 


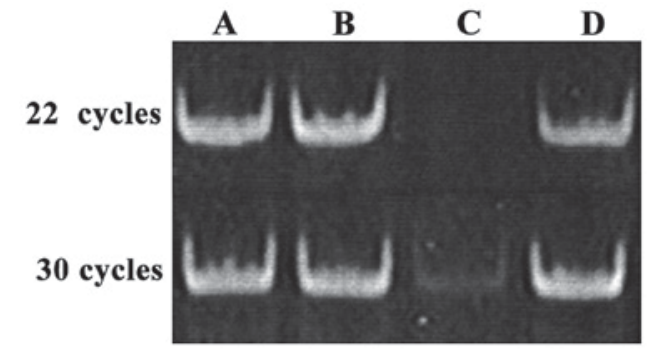

Figure 2. Analysis of specificity of miR-222 stem-loop RT-PCR. Lane A, $5 \mu \mathrm{g}$ of total RNA; lane B, RNA ( $<200 \mathrm{nt}$ ) isolated from $5 \mu \mathrm{g}$ of total RNA; lane C, miRNA precursor (60-100 nt) isolated from $5 \mu \mathrm{g}$ of total RNA by $15 \%$ PAGE; lane D, mature miRNA (18-24 nt) isolated from $5 \mu \mathrm{g}$ of total RNA by $15 \%$ PAGE. PCR with 30 cycles provided a faint band of miRNA precursor, while PCR with 22 cycles failed to show this band.

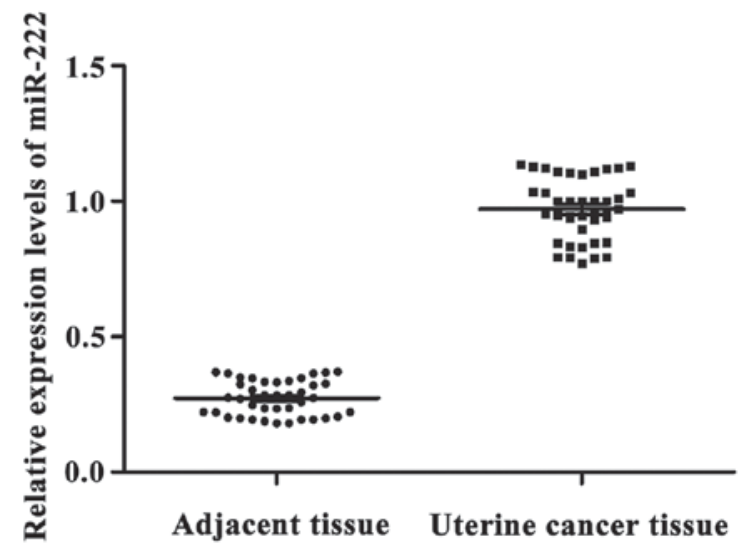

Figure 3. Relative expression levels of miR-222 in adjacent and uterine cancer tissues. The expression level of miR-222 in adjacent tissues was significantly lower than that in uterine cancer tissues.

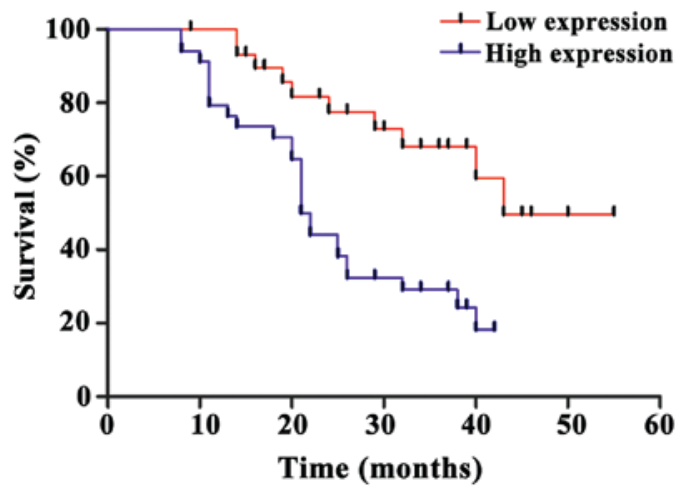

Figure 4. Correlation between miR-222 expression and prognosis. The expression level of miR-222 was negatively correlated with the survival of uterine cancer patients.

with 22 cycles failed to show this band. We speculated that low RNA recovery rate is the reason why amplification efficiency of mature miRNA was lower than total RNA amplification efficiency. Small RNA recovery efficiency was only $50 \%$.

miR-222 expression in uterine cancer and adjacent tissues. With let-7a as endogenous control, the relative expression levels of miR-222 in adjacent and uterine cancer tissues were $0.275 \pm 0.094$ and $0.953 \pm 0.183$, respectively. The expression

Table II. Correlation between miR-222 expression and a variety of clinicopathological features of uterine cancer.

\begin{tabular}{lccc}
\hline $\begin{array}{l}\text { Clinicopathological } \\
\text { features }\end{array}$ & Cases & miR-222 & \\
& expression & P-value
\end{tabular}

\section{Age (years) \\ $<40$ \\ $40-60$}

$>60$

Tumor size $(\mathrm{cm})$

$<4$
$\geq 4$

Gross type

Exogenous type
Endogenous type
Ulcer type
Neck type

Tissue differentiation

$\begin{array}{lrrr}\text { Large cell keratinizing (I) } & 9 & 0.214 \pm 0.047 & 0.001 \\ \text { Non-Keratinizing type (II) } & 19 & 0.289 \pm 0.051 & \end{array}$

Small cell type (III)

$38 \quad 0.656 \pm 0.117$

Pathological type

\begin{tabular}{lrrr} 
Squamous cell carcinoma & 53 & $0.427 \pm 0.082$ & 0.628 \\
Adenocarcinoma & 9 & $0.416 \pm 0.079$ & \\
Adenosquamous carcinoma & 4 & $0.398 \pm 0.077$ & \\
FIGO stage & & & \\
Stage I & 6 & $0.234 \pm 0.049$ & 0.284 \\
Stage II & 25 & $0.425 \pm 0.082$ & \\
Stage III & 18 & $0.419 \pm 0.084$ & \\
Stage IV & 17 & $0.427 \pm 0.087$ & \\
\hline
\end{tabular}

level of miR-222 in adjacent tissues was significantly lower than that in uterine cancer tissues. The difference was statistically significant $(\mathrm{p}<0.05)($ Fig. 3$)$.

Correlation between miR-222 expression and a variety of clinicopathological features of uterine cancer. The expression level of miR-222 was different in uterus cancer tissues with the different differentiation degrees. The expression level of miR-222 in grade III uterine cancer is obviously higher than that in grade I and II. The expression level of miR-222 was increased with the increased degree of malignancy. There was no significant correlation between miR-222 expression and age, tumor size, gross type, pathological type and FIGO stage $(\mathrm{p}>0.05)$ (Table II).

Correlation between miR-222 expression and prognosis. Follow-up study of 66 uterine cancer patients showed that the median survival time of miR-222 high expression uterine cancer patients was $21.4 \pm 0.8$ months, while the median survival time of miR-222 low expression uterine cancer patients was $44.9 \pm 1.7$ months. The expression level of miR-222 was significantly negatively correlated with the survival of uterine cancer patients ( $<<0.05)$ (Fig. 4). 


\section{Discussion}

Uterine cancer is the second most common malignancy in women, and its incidence is only lower than that of breast cancer (13). However, pathogenesis of uterine cancer has not been fully understood, leading to poor treatment outcomes as well as high recurrence and mortality rate (14). As a class of highly conserved endogenous regulatory RNAs, miRNAs bind to mRNAs transcribed from target genes to inhibit further translation, thereby regulating the expression of target genes and participating in a series of physiological and pathological processes (15). miRNA can play a role as oncogene or tumor suppressor gene in the occurrence and development of a tumor (16).

Analysis of the expression pattern of miRNAs in invasive cervical squamous cell carcinoma showed that most miRNAs were upregulated and only two were downregulated (16). The expression level of miR-127 is significantly correlated with lymph node metastasis (17). Some scholars found that in colon cancer tissues, miR-143 and miR-145 expression were significantly downregulated $(18,19)$. In addition, abnormal expression of a large number of miRNAs in solid tumors was observed, and most miRNAs, such as miR-21, miR-92 and miR-155, were usually upregulated $(20,21)$.

In recent years, studies have shown that the expression level of miR-222 is increased to varying degrees in tumor tissue or tumor cell lines of different types of cancer $(22,23)$. miR-222 is involved in the occurrence and development of a variety of cancers, such as bladder cancer (24), prostate cancer (25), and melanoma (26). Among these cancers, target genes are usually tumor suppressor genes or pre-apoptotic factors. miR-222 inhibits cell apoptosis and participates in the occurrence and development of tumor through the regulation of expression of its target genes (23). Results of this study showed that the stem-loop RT-PCR can specifically amplify miRNA. miR-222 was significantly upregulated in uterine cancer tissue, suggesting that miR-222 may be involved in the occurrence and development of uterine cancer. It has been reported that miR-222 can regulate the expression of PTEN to affect the radiosensitivity, cell growth and invasion of gastric cancer SGC7901 cells. When miR-222 was downregulated, the malignant behavior of SGC7901 cells was significantly inhibited, suggesting that miR-222 may play a role as oncogene in gastric cancer (27). Different expression levels of miRNA were observed in uterus cancer tissues with the different differentiation degrees. The expression level of miR-222 in grade III uterine cancer was obviously higher than that in grade I and II. The expression level of miR-222 was increased with the increased degree of malignancy. Therefore, we speculate that miR-222 expression upregulation in uterine cancer may silence downstream tumor suppressor genes such as p27 (28), p57 (29) and Bmf (30). In addition, the expression level of miR-222 was negatively correlated with the survival time of patients with uterine cancer, suggesting that the expression of miR-222 in uterine cancer may serve as an indicator for the prognosis of this disease.

In conclusion, upregulated expression of miR-222 in uterine cancer may play an important role in the occurrence and development of uterine cancer. Our future studies will focus on the function of target genes of miR-222 to identify new targets for the treatment of uterine cancer.

\section{Acknowledgements}

Not applicable.

\section{Funding}

No funding was received.

\section{Availability of data and materials}

The datasets used and/or analyzed during the present study are available from the corresponding author on reasonable request.

\section{Authors' contributions}

$\mathrm{XN}$ conceived and designed the study, and drafted the report. $\mathrm{XN}$ and HT collected, analyzed and interpreted the experimental data, and revised the manuscript critically for important intellectual content. Both authors read and approved the final manuscript.

\section{Ethics approval and consent to participate}

The study was approved by the Ethics Committee of Dongying People's Hospital (Dongying, China). Signed written informed consents were obtained from the patients or the guardians.

\section{Consent for publication}

Not applicable.

\section{Competing interests}

The authors declare that they have no competing interests.

\section{References}

1. Kowalewska M, Bakula-Zalewska E, Chechlinska M, Goryca K, Nasierowska-Guttmejer A, Danska-Bidzinska A and Bidzinski M: MicroRNAs in uterine sarcomas and mixed epithelial-mesenchymal uterine tumors: A preliminary report. Tumour Biol 34: 2153-2160, 2013.

2. Peralta-Zaragoza O, Deas J, Meneses-Acosta A De la O-Gómez F, Fernández-Tilapa G, Gómez-Cerón C, Benítez-Boijseauneau O, Burguete-García A, Torres-Poveda K, Bermúdez-Morales VH, et al: Relevance of miR-21 in regulation of tumor suppressor gene PTEN in human cervical cancer cells. BMC Cancer 16: 215, 2016.

3. Fang H, Shuang D, Yi Z, Sheng $\mathrm{H}$ and Liu Y: Up-regulated microRNA-155 expression is associated with poor prognosis in cervical cancer patients. Biomed Pharmacother 83: 64-69, 2016.

4. Pang $\mathrm{H}$ and Yue $\mathrm{X}$ : MiR-205 serves as a prognostic factor and suppresses proliferation and invasion by targeting insulin-like growth factor receptor 1 in human cervical cancer. Tumour Biol 39: 1010428317701308, 2017.

5. Sun Y, Zhang B, Cheng J, Wu Y, Xing F, Wang Y, Wang Q and Qiu J: MicroRNA-222 promotes the proliferation and migration of cervical cancer cells. Clin Invest Med 37: E131, 2014.

6. Sun L, Jiang R, Li J, Wang B, Ma C, Lv Y and Mu N: MicoRNA-425-5p is a potential prognostic biomarker for cervical cancer. Ann Clin Biochem 54: 127-133, 2017.

7. Liu P, Sun M, Jiang W, Zhao J, Liang C and Zhang H: Identification of targets of miRNA-221 and miRNA-222 in fulvestrant-resistant breast cancer. Oncol Lett 12: 3882-3888, 2016.

8. Zhang DQ, Zhou CK, Jiang XW, Chen J and Shi BK: Increased expression of miR-222 is associated with poor prognosis in bladder cancer. World J Surg Oncol 12: 241, 2014. 
9. Ahmed FE, Amed NC, Vos PW, Bonnerup C, Atkins JN, Casey M, Nuovo GJ, Naziri W, Wiley JE and Allison RR: Diagnostic microRNA markers to screen for sporadic human colon cancer in blood. Cancer Genomics Proteomics 9: 179-192, 2012.

10. Lorimer IA: Regulation of p27Kip1 by miRNA 221/222 in glioblastoma. Cell Cycle 8: 2685, 2009.

11. Zhao Y, Wang Y, Yang Y, Liu J, Song Y, Cao Y, Chen X, Yang W, Wang F, Gao J, et al: MicroRNA-222 controls human pancreatic cancer cell line capan- 2 proliferation by $\mathrm{p} 57$ targeting. J Cancer 6 : 1230-1235, 2015

12. Peltier HJ and Latham GJ: Normalization of microRNA expression levels in quantitative RT-PCR assays: Identification of suitable reference RNA targets in normal and cancerous human solid tissues. RNA 14: 844-852, 2008.

13. Dong Y, Si JW, Li WT, Liang L, Zhao J, Zhou M, Li D and Li T: miR-200a/miR-141 and miR-205 upregulation might be associated with hormone receptor status and prognosis in endometrial carcinomas. Int J Clin Exp Pathol 8: 2864-2875, 2015.

14. Tseng JH, Bisogna M, Hoang LN, Olvera N, Rodriguez-Aguayo C, Lopez-Berestein G, Sood AK, Levine DA and Jelinic P: miR-200c-driven mesenchymal-to-epithelial transition is a therapeutic target in uterine carcinosarcomas. Sci Rep 7: 3614, 2017.

15. Sun H, Xin J, Lu Z, Wang N, Liu N and Guo Q: Potential molecular mechanisms for improved prognosis and outcome with neoadjuvant chemotherapy prior to laparoscopical radical hysterectomy for patients with cervical cancer. Cell Physiol Biochem 32: 1528-1540, 2013.

16. Xiong X, Cheng J, Liu X, Tang S and Luo X: Correlation analysis between miR-124 rs531564 polymorphisms and susceptibility to cervical cancer. Nan Fang Yi Ke Da Xue Xue Bao 34: 210-213, 2014 (In Chinese)

17. He Z, Xu H, Meng Y and Kuang Y: miR-944 acts as a prognostic marker and promotes the tumor progression in endometrial cancer. Biomed Pharmacother 88: 902-910, 2017.

18. Liu B, Che Q, Qiu H, Bao W, Chen X, Lu W, Li B and Wan X: Elevated MiR-222-3p promotes proliferation and invasion of endometrial carcinoma via targeting ER $\alpha$. PLoS One 9: e87563, 2014.

19. Yue Z, Yun-Shan Z and Feng-Xia X: miR-205 mediates the inhibition of cervical cancer cell proliferation using olmesartan. J Renin Angiotensin Aldosterone Syst 17: 1470320316663327, 2016.

20. Zhang T, Zou P, Wang T, Xiang J, Cheng J, Chen D and Zhou J: Down-regulation of miR-320 associated with cancer progression and cell apoptosis via targeting Mcl-1 in cervical cancer. Tumour Biol 37: 8931-8940, 2016.

21. Yin ZL, Wang YL, Ge SF, Guo TT, Wang L, Zheng XM and Liu J: Reduced expression of miR-503 is associated with poor prognosis in cervical cancer. Eur Rev Med Pharmacol Sci 19: 4081-4085, 2015.
22. Li W, Liang J, Zhang Z, Lou H, Zhao L, Xu Y and Ou R: MicroRNA-329-3p targets MAPK1 to suppress cell proliferation, migration and invasion in cervical cancer. Oncol Rep 37: 2743-2750, 2017.

23. Zhang X, Dong Y, Ti H, Zhao J, Wang Y, Li T and Zhang B: Down-regulation of miR-145 and miR-143 might be associated with DNA methyltransferase 3B overexpression and worse prognosis in endometrioid carcinomas. Hum Pathol 44: 2571-2580, 2013.

24. Sun J, Chu H, Ji J, Huo G, Song Q and Zhang X: Long non-coding RNA HOTAIR modulates HLA-G expression by absorbing miR-148a in human cervical cancer. Int J Oncol 49: 943-952, 2016.

25. Shen SN, Wang LF, Jia YF, Hao YQ, Zhang L and Wang H: Upregulation of microRNA-224 is associated with aggressive progression and poor prognosis in human cervical cancer. Diagn Pathol 8: 69, 2013.

26. Azizmohammadi S, Safari A, Azizmohammadi S, Kaghazian M, Sadrkhanlo M, Yahaghi E, Farshgar R and Seifoleslami M: Molecular identification of miR-145 and miR-9 expression level as prognostic biomarkers for early-stage cervical cancer detection. QJM 110: 11-15, 2017.

27. Chun-Zhi Z, Lei H, An-Ling Z, Yan-Chao F, Xiao Y, Guang-Xiu W, Zhi-Fan J, Pei-Yu P, Qing-Yu Z and Chun-Sheng K: MicroRNA-221 and microRNA-222 regulate gastric carcinoma cell proliferation and radioresistance by targeting PTEN. BMC Cancer 10: 367, 2010.

28. Wang Y, Zeng J, Pan J, Geng X, Liu Y, Wu J, Song P, Wang Y, Jia $\mathbf{J}$ and Wang L: MicroRNA-200c is involved in proliferation of gastric cancer by directly repressing p27Kip1. Biochem Biophys Rep 8: 227-233, 2016.

29. Zhang E, He X, Yin D, Han L, Qiu M, Xu T, Xia R, Xu L, Yin R and De W: Increased expression of long noncoding RNA TUG1 predicts a poor prognosis of gastric cancer and regulates cell proliferation by epigenetically silencing of p57. Cell Death Dis 7: e2109, 2016.

30. Zhu L, Cheng X, Shi J, Jiacheng L, Chen G, Jin H, Liu AB, Pyo H, Ye J, Zhu Y, et al: Crosstalk between bone marrow-derived myofibroblasts and gastric cancer cells regulates cancer stemness and promotes tumorigenesis. Oncogene 35: 5388-5399, 2016.

This work is licensed under a Creative Commons Attribution-NonCommercial-NoDerivatives 4.0 International (CC BY-NC-ND 4.0) License. 